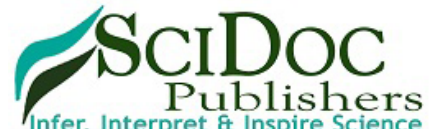

\author{
International Journal of Dentistry and Oral Science (IJDOS) \\ ISSN: $2377-8075$
}

\title{
Assessment of Canine Guided Occlusion among FPD Patients - A Retrospective Study
}

Research Article

Aarthi Muthukumar ${ }^{1}$, Revathi Duraisamy ${ }^{2 *}$, Adimulapu Hima Sandeep ${ }^{3}$

${ }^{1}$ Saveetha Dental College and Hospitals, Saveetha Institute of Medical and Technical Sciences Saveetha University, Chennai-600077, Tamilnadu, India. ${ }^{2}$ Senior Lecturer, Department of Prosthodontics, Saveetha Dental College And Hospitals, Saveetha Institute Of Medical And Technical Sciences, Saveetha University, Chennai-600077, Tamilnadu, India.

${ }^{3}$ Postgraduate Student, Department of Conservative Dentistry and Endodontics, Saveetha Dental College and Hospitals, Saveetha Institute of Medical and Technical Sciences Saveetha University, Chennai-600077, Tamilnadu, India.

\section{Abstract}

Canine guided occlusion is a mutually protected occlusion where the vertical and horizontal overlap of canine causes disengages posterior teeth in lateral movement of mandible. Group function occlusion is based on multiple contacts between the maxillary and mandibular teeth in lateral movements on the working side. Fixed partial denture is a dental restoration used to replace missing teeth and that is permanently attached to the adjacent teeth. The aim of the study was to assess the prevalence of missing teeth as well as presence of canine guided occlusion among FPD patients. A retrospective cross sectional study was done on 86000 patient records between June 2019 to March 2020 and arrived at the data of 487 by considering the inclusion criteria of the study such as patients who had undergone fixed partial denture and had intact permanent canine and molars and all the available data were included and no sorting process was done to minimise the sampling bias. Statistical test done was chi square test and the software used was SPSS version 26 by IBM. Type of analysis done was descriptive analysis. From this study, we observed that the prevalence of missing teeth were found to be higher among males $(54 \%)$ than in females $(45 \%)$. It is found that canine guided occlusion was prevalent in all age groups such as $<25$ years $(10 . .6 \%), 25-40$ years $(34.70 \%)$ and $>40$ years $(30.35 \%)$. This study shows the prevalence of canine guided occlusion irrespective of gender and age.

Keywords: Missing Teeth; Fixed Dental Prosthesis; Dental Occlusion; Canine Guided Occlusion; Group Function.

\section{Introduction}

Lateral occlusion plays a major role in masticatory function, comfort and aesthetics [1]. The two commonly applied lateral occlusion schemes are canine guided occlusion and group function occlusion. The canine guided occlusion is a mutually protected occlusion where the vertical and horizontal overlap of canine teeth causes disengagement of posterior teeth in the lateral movement of the mandible [2]. Group function occlusion is based on multiple contacts between the maxillary and mandibular teeth in lateral movements on the working side [2, 3]. Canine guided occlusion protects the posterior teeth laterally because of the strategic location, anatomy and proprioceptive properties of canine [4]. Group function contributes to a wide distribution of occlusal forces on several teeth, thus it is more comfortable and functional.
With different degrees of excursion, the lateral occlusal scheme might differ [5]. Functional occlusion may also change without any physiological abnormalities [5, 6]. Fixed prosthodontics is the area of prosthodontics focused on permanently attached dental prosthesis [7]. It is also referred to as indirect restoration. It includes crowns, bridges, inlays, onlays and veneers. FPD can be used to restore a single or multiple teeth that is permanently attached to the adjacent teeth [8]. The adjacent teeth are called abutments and act as a support to the FPD bridge. Three main components are: pontic, retainers and connector [9].

Contact area and contact number have been used frequently as a measure of the adequacy of dental occlusion [10-14]. Occlusal features are dynamic and subject to change with aging and dental

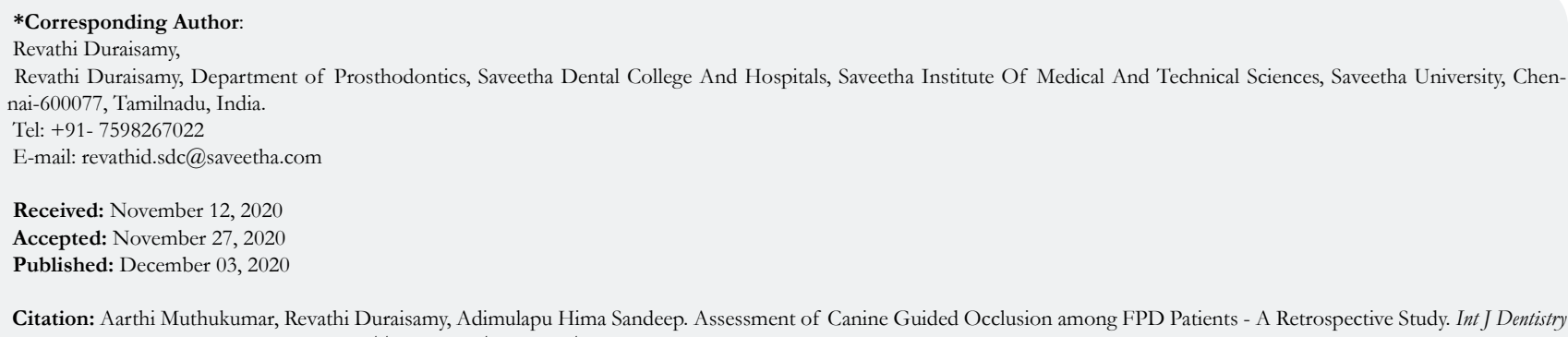

Citation: Aarthi Muthukumar, Revathi Duraisamy, Adimulapu Hima Sandeep. Assessment of Canine Guided Occlusion among FPD Patients - A Retrospective Study. Int J Dentistry Oral Sci. 2020;S5:02:0012:66-70. doi: http://dx.doi.org/10.19070/2377-8075-SI02-050012

Copyright: Revathi Duraisamy 2020 . This is an open-access article distributed under the terms of the Creative Commons Attribution License, which permits unrestricted use, distribution and reproduction in any medium, provided the original author and source are credited. 
treatment. Restoration, tooth wear and fracture will inevitably affect on the lateral occlusion [15]. Main objective of prosthodontic treatment is to improve oral function, to observe the changes in occlusal contacts $[16,17]$.

Every tooth restoration, prosthetic device, extraction and orthodontic treatment changes static and dynamic occlusion. In complete denture, balanced occlusion is provided where all static relations are balanced [18]. For removable partial denture to be successful, the occlusal pattern of the natural teeth should be harmonized with the temporomandibular joints, and the same occlusal pattern should be incorporated into the artificial teeth [19]. The ideal occlusal contact for an implant is over the body which leads to the axial loading of implants [20]. For implant supported full mouth rehabilitation, balanced occlusion or mutually protected occlusion is provided, which is obtained by placing implants on the canine region.

The canines have a good crown root ratio and are capable of tolerating high occlusal forces. Canines provide higher proprioception when compared to posterior teeth. The palatal surface of canine is concave and is suitable for guiding lateral movements. Lateral forces should be directed toward the anterior teeth especially canines as lateral forces on posterior teeth can result in a fracture or excessive wear .Canine-protected occlusion reduces the chances of temporomandibular dysfunction, since it reduces the lateral tooth contact [21].

Previously our team had conducted numerous clinical trials [2228] and lab animal studies [29-33] and in vitro studies [32-36] over the past 5 years. Now we are focussing on retrospective study. The idea for this study is stemmed from the current interest in our community.

\section{Materials and Methods}

A retrospective study was done in the university setting. The retrospective cross sectional study was done by reviewing patient records and analysed the data of 86000 patients between June 2019 to March 2020 and we arrived at the data of 488. Data of patients who underwent FPD treatment was analysed and retrieved.The cons of the study will be geographic limitations,locations,trendsnot accessed. Number of people involved were two reviewers. Ethical approval was approved by the institutional ethical committee, SIMATS. Inclusion criteria were fixed partial denture, canine guidance, occlusion. All the available data ss were included and no sorting process was done to minimise sampling bias. Independent variables are the, gender, ethnicity and age. Dependent variables are fixed partial denture and occlusion. The results were tabulated in excel sheet and are transferred to SPSS for analysis.

Statistical software used was SPSS version 26 by IBM and the statistical test done was chi square test. Type of analysis done is descriptive analysis.

\section{Results and Discussion}

In the study, we observed that male received FPD at a higher rate (54\%) than females (45.7\%) and transgenders (0.21\%) (Figure 1). People of age range 25-40 years received FPD at a higher rate $(48.82 \%)$ and people of $<20$ years $(12.54 \%),>40$ years $(40.25 \%)$ which was lesser comparatively (Figure 2). The association between gender and missing teeth was done where males with missing teeth sextant $1(5.02 \%)$, sextant $2(19.87 \%)$ (sextant $3(4.81 \%)$, sextant $4(6.26 \%)$, sextant 5(10.04), sextant 6(7.53\%) and Females with missing teeth in sextant $1(6.65 \%)$, sextant $2(13.39 \%)$, sextant $3(5.23 \%)$, sextant $4(9.21 \%)$, sextant $5(4.39)$ sextant $6(7.32 \%)$ was seen, therefore sextant 2 (red) was more prevalent when compared to sextant 1(blue), sextant 3 (green), sextant 4(orange), sextant 5(yellow) and sextant 6(emerald) (Figure 3).

The association between gender and the corresponding lateral occlusion was done where canine guided occlusion (blue) was predominant in both males $(40.45 \%)$ and females $(34.50 \%)$ when compared to group function occlusion (red) (Figure 4). The association between missing teeth in sextant wise and corresponding occlusion was done which showed that canine guided occlusion (blue) was prevalent in sextant $1(8.58 \%)$, sextant $2(25.31 \%)$, sextant $3(7.53 \%)$, sextant $4(12.76 \%)$, sextant $5(9.41 \%)$, sextant $6(11.51 \%$ ) when compared to group function occlusion (red) (Figure 5). The association between age and corresponding occlusion was done where canine guided occlusion/(blue) was prevalent in age groups $<25$ years $(10.06 \%), 25-40$ years $(34.7 \%)$ and $>40$ years $(30.39 \%)$ when compared to group function (red) (Figure 6)

The association between gender and missing teeth was done by chi-square test. It was seen that males are more susceptible to missing teeth when compared to females. According to a study by Khazaeiet al, reported a high prevalence of tooth loss in Iranian adult population. They stated that tooth loss was more prevalent among men than women [34]. In contrast, Most of the authors have concluded that there is no significant gender correlation with missing teeth. The discrepancy between studies may be due to differences in sample size, culture and food habits and the family history of the individual patient.

Figure 1. Bar graph represents the frequency of gender predilection among patients with fixed partial denture(FPD). It shows, male $(54 \%)$ predilection in the study population when compared to females $(45.7 \%)$ and transgender $(0.21 \%)$.

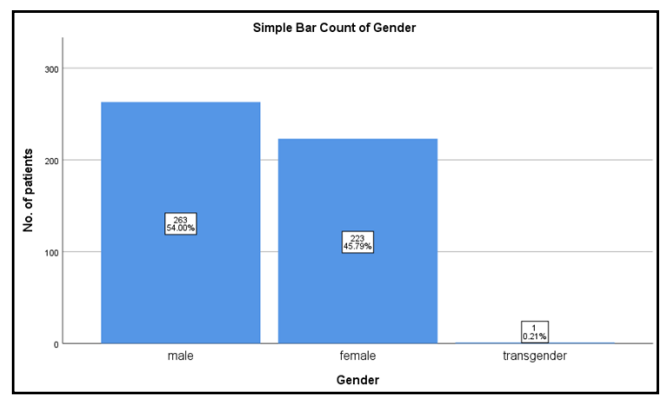


Figure 2. Bar graph represents the frequency of age distribution among patients with fixed partial denture(FPD). It shows, $25-40$ years $(46.8 \%)$ has more prevalence when compared to $<25 \mathrm{yrs}(12.9 \%)$ and $>40 \mathrm{yrs}(40.2 \%)$.

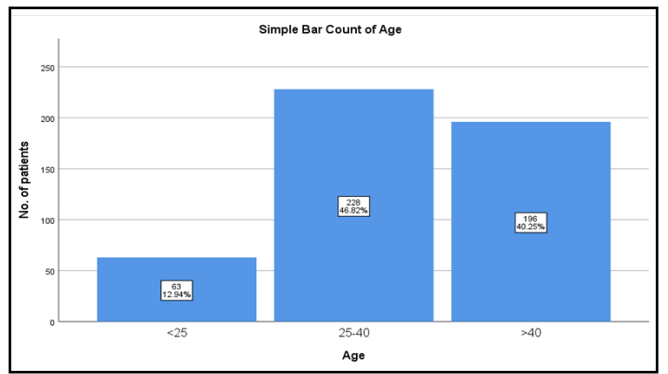

Figure 3. Bar graph represents the association between gender and missing teeth among patients with fixed partial denture (FPD). Prevalence of missing teeth were found to be higher among males when compared to females and transgenders and sextant 2 has the most number of missing teeth. Pearson's chi square test shows -p value is $0.02(<0.05)$. Hence, it is statistically significant.

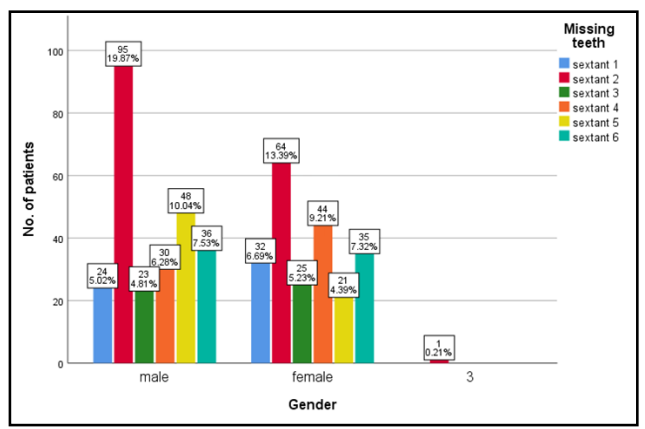

Figure 4. Bar graph represents the association between gender and corresponding occlusion among patients with fixed partial denture (FPD). Higher prevalence of canine guided occlusion was seen among FPD patients irrespective of gender. Pearson's chi square test shows- $\mathrm{p}$ value is $0.84(>0.05)$, statistically insignificant.

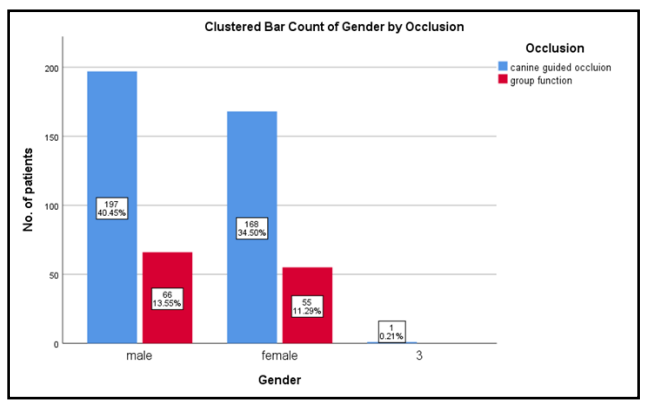

Figure 5. Bar graph represents the association between missing teeth in sextant wise and corresponding occlusion among patients with fixed partial denture(FPD). Higher prevalence of canine guided occlusion among FPD patients irrespective of missing teeth in sextants.Pearson's chi square test shows-p value is $0.299(>0.05)$, statistically insignificant.

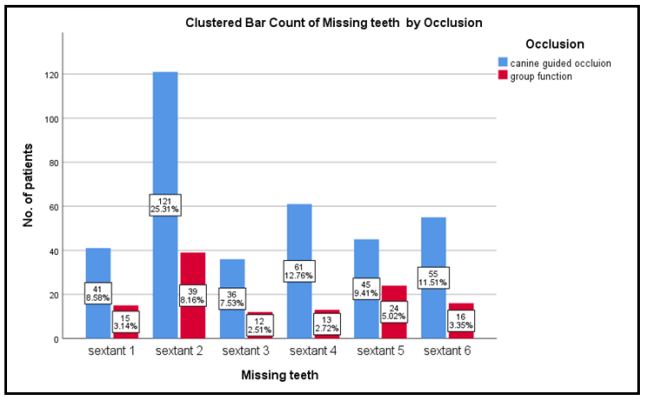

Association between age and corresponding occlusion was done by chi square test. It is found that canine guided occlusion(blue) was prevalent in all age groups such as $<25$ years (10..6\%), 25-40 years $(34.70 \%)$ and $>40$ years $(30.35 \%)$. Ahmad A, Shan and others reported that there is more percentage of canine guided occlusion among the study population irrespective of age [37]. By contrast, few authors suggest that as the age increases, canine wears down and occlusion gets transformed into group function [38].
The discrepancy among various studies and the current study can be due to the difference in study population, different sample size, inclusion criteria of the study.

Association between gender and corresponding lateral occlusion was done by chi square test. It is found that canine guided occlusion (blue) was prevalent in both males (40.45\%) and females $(34.5 \%)$. Ogawa et al found no difference in the occurrence of ca- 
Figure 6. Bar graph represents the association between age and corresponding occlusion among patients with fixed partial denture(FPD). Higher prevalence of canine guided occlusion among FPD patients irrespective of age groups and patients within the age group of 25-40 years has higher prevalence of FPD. Pearson's chi square value:0.736, df :3, p value:0.865( $>0$. 05), statistically insignificant.

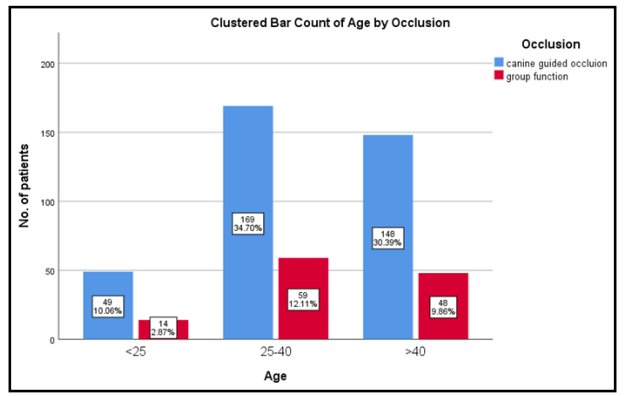

nine and group guidance in relation to genders [39]. By contrast, Rinchuse et al reported loss of canine guidance in individuals who eat coarse and abrasive food 4 . In the current study $40.45 \%$ of males and $34.4 \%$ of females have canine guided occlusal schemes whereas only $13.55 \%$ of males and $11.29 \%$ of females have group function. Which shows the presence of canine guided occlusion irrespective of gender. The discrepancy between studies can be due to the difference in sample size, culture and eating habits.

\section{Conclusion}

Within the limits of the study,it is seen that irrespective of gender, age or sextant of the missing teeth, a generality of canine guided occlusion is seen among patients who have undergone FPD treatment.

\section{Acknowledgement}

I Sincerely thank my Guide and Mentor for giving full support for this research work. I would also be thankful to the Department of Research and Department of IT Saveetha Dental College and Hospitals, Saveetha Institute of Medical and Technical Sciences, Saveetha University.

\section{References}

[1]. Abduo J, Bennamoun M, Tennant M, McGeachie J. Effect of prosthodontic planning on lateral occlusion scheme: a comparison between conventional and digital planning. J Appl Oral Sci. 2015 Mar-Apr;23(2):196-205.Pubmed PMID: 26018312.

[2]. DiPietro GJ. A study of occlusion as related to the Frankfort-mandibular plane angle. J Prosthet Dent. 1977 Oct:38(4):452-8.Pubmed PMID: 269281.

[3]. Morgano SM, VanBlarcom CW, Ferro KJ, Bartlett DW. The history of The Glossary of Prosthodontic Terms. J Prosthet Dent. 2018 Mar;119(3):311312.Pubmed PMID: 29475757.

[4]. Rinchuse DJ, Kandasamy S, Sciote J. A contemporary and evidence-based view of canine protected occlusion. Am J Orthod Dentofacial Orthop. 2007 Jul;132(1):90-102.Pubmed PMID: 17628256.

[5]. Ogawa T, Ogimoto T, Koyano K. Pattern of occlusal contacts in lateral positions: canine protection and group function validity in classifying guidance patterns. J Prosthet Dent. 1998 Jul;80(1):67-74.Pubmed PMID: 9656180.

[6]. Dolezel I, Panek D, Ulrych B. Pulsed actuator with permanent magnet and its dynamic characteristics [Internet]. 2011 International Conference on Electrical Machines and Systems. 2011. Available from: http://dx.doi. org/10.1109/icems.2011.6073604

[7]. Academy of Prosthodontics. The Glossary of Prosthodontic Terms. Mosby Journal Reprint Department; 1994. 70 p.

[8]. Woda A, Vigneron P, Kay D. Nonfunctional and functional occlusal contacts: a review of the literature. J Prosthet Dent. 1979 Sep;42(3):335-41. Pubmed PMID: 383965.
[9]. Weinberg LA. A cinematic study of centric and eccentric occlusions. J Prosthet Dent. 1964 Mar 1;14(2):290-3.

[10]. Ciancaglini R, Gherlone EF, Redaelli S, Radaelli G. The distribution of occlusal contacts in the intercuspal position and temporomandibular disorder. J Oral Rehabil. 2002 Nov;29(11):1082-90.Pubmed PMID: 12453263.

[11]. McNamara DC, Henry PJ. Terminal hinge contact in dentitions. J Prosthet Dent. 1974 Oct;32(4):405-11.Pubmed PMID: 4528761.

[12]. Iwase Y, Saitoh I, Okamoto A, Nakakura-Ohshima K, Inada E, Yamada C, et al. Do occlusal contact areas of maximum closing position during gum chewing and intercuspal position coincide? Arch Oral Biol. 2011 Dec;56(12):1616-23.Pubmed PMID: 21855855.

[13]. Owens S, Buschang PH, Throckmorton GS, Palmer L, English J. Masticatory performance and areas of occlusal contact and near contact in subjects with normal occlusion and malocclusion. Am J Orthod Dentofacial Orthop. 2002 Jun;121(6):602-9.Pubmed PMID: 12080313.

[14]. Hidaka O, Iwasaki M, Saito M, Morimoto T. Influence of clenching intensity on bite force balance, occlusal contact area, and average bite pressure. J Dent Res. 1999 Jul;78(7):1336-44.Pubmed PMID: 10403461.

[15]. Yi SW, Ericsson I, Carlsson GE, Wennström JL. Long-term follow-up of cross-arch fixed partial dentures in patients with advanced periodontal destruction. Evaluation of the supporting tissues. Acta Odontol Scand. 1995 Aug;53(4):242-8.Pubmed PMID: 7484107.

[16]. Pokorny PH, Wiens JP, Litvak H. Occlusion for fixed prosthodontics: a historical perspective of the gnathological influence. J Prosthet Dent. 2008 Apr;99(4):299-313.Pubmed PMID: 18395541.

[17]. Koyano K, Tsukiyama Y, Kuwatsuru R. Rehabilitation of occlusion-science or art?. J. Oral Rehabil. 2012 Jul;39(7):513-21.

[18]. Rangarajan V, Gajapathi B, Yogesh PB, Ibrahim MM, Kumar RG, Karthik P. Concepts of occlusion in prosthodontics: A literature review, part I. The J. Indian Prosthodont. Soc. 2015 Jul;15(3):200.

[19]. Jeffreys FE, Platner RL. Occlusion in removable partial dentures. The J Prosthet Dent. 1960 Sep 1;10(5):912-20.

[20]. Verma M, Nanda A, Sood A. Principles of occlusion in implant dentistry. J Int Clin Dent Res Organ. 2015 Dec 1;7(3):27.

[21]. Clark JR, Evans RD. Functional Occlusion: I. A Review [Internet]. Vol. 28, Journal of Orthodontics. 2001. p. 76-81. Available from: http://dx.doi. org/10.1093/ortho/28.1.76

[22]. Jain AR, Nallaswamy D, Ariga P, Ganapathy DM. Determination of correlation of width of maxillary anterior teeth using extraoral and intraoral factors in Indian population: A systematic review. World J Dent. 2018 Jan;9:68-75.

[23]. Jyothi S, Robin PK, Ganapathy D. Periodontal health status of three different groups wearing temporary partial denture. Res J Pharm Technol. 2017;10(12):4339-42.

[24]. Duraisamy R, Krishnan CS, Ramasubramanian H, Sampathkumar J, Mariappan S, Navarasampatti Sivaprakasam A. Compatibility of Nonoriginal Abutments With Implants: Evaluation of Microgap at the Implant-Abutment Interface, With Original and Nonoriginal Abutments. Implant Dent. 2019 Jun;28(3):289-295.Pubmed PMID: 31124826.

[25]. Selvan SR, Ganapathy D. Efficacy of fifth generation cephalosporins against methicillin-resistant Staphylococcus aureus-A review. Res J Pharm Technol. 2016;9(10):1815-8.

[26]. Ganapathy D, Sathyamoorthy A, Ranganathan H, Murthykumar K. Effect of Resin Bonded Luting Agents Influencing Marginal Discrepancy in All Ceramic Complete Veneer Crowns. J Clin Diagn Res. 2016 Dec;10(12):ZC67ZC70.Pubmed PMID: 28209008.

[27]. Subasree S, Murthykumar K. Effect of Aloe Vera in Oral Health-A Review. Res J Pharm Technol. 2016;9(5):609-12.

[28]. Ranganathan H, Ganapathy DM, Jain AR. Cervical and Incisal Marginal 
Discrepancy in Ceramic Laminate Veneering Materials: A SEM Analysis. Contemp Clin Dent. 2017 Apr-Jun;8(2):272-278.Pubmed PMID: 28839415.

[29]. Vijayalakshmi B, Ganapathy D. Medical management of cellulitis. Res J Pharm Technol. 2016;9(11):2067-70.

[30]. Ashok V, Suvitha S. Awareness of all ceramic restoration in rural population. Res J Pharm Technol. 2016;9(10):1691-3.

[31]. Ashok V, Nallaswamy D, Benazir Begum S, Nesappan T. Lip Bumper Prosthesis for an Acromegaly Patient: A Clinical Report. J Indian Prosthodont Soc. 2014 Dec;14(Suppl 1):279-82.Pubmed PMID: 26199531.

[32]. Venugopalan S, Ariga P, Aggarwal P, Viswanath A. Case Report: Magnetically retained silicone facial prosthesis. Niger. J. Clin. Pract. $2014 \mathrm{Mar}$ 27;17(2):260-4

[33]. Kannan A, Venugopalan S. A systematic review on the effect of use of impregnated retraction cords on gingiva. Res J Pharm Technol. 2018;11(5):2121-6.

[34]. Basha FYS, Ganapathy D, Venugopalan S. Oral Hygiene Status among Pregnant Women [Internet]. Vol. 11, Research Journal of Pharmacy and Technology. 2018. p. 3099. Available from: http://dx.doi.org/10.5958/0974360x.2018.00569.3

[35]. Ajay R, Suma K, Ali SA, Kumar Sivakumar JS, Rakshagan V, Devaki V, et al. Effect of Surface Modifications on the Retention of Cement-retained Im- plant Crowns under Fatigue Loads: An In vitro Study. J Pharm Bioallied Sci. 2017 Nov;9(Suppl 1):S154-S160.Pubmed PMID: 29284956.

[36]. Kannan A. Effect of Coated Surfaces influencing Screw Loosening in Implants: A Systematic Review and Meta-analysis. World. 2017 Nov;8(6):496502.

[37]. Khazaei S, Keshteli AH, Feizi A, Savabi O, Adibi P. Epidemiology and risk factors of tooth loss among Iranian adults: findings from a large community-based study. Biomed Res Int. 2013;2013:786462.Pubmed PMID: 24228259.

[38]. Muneeb A, Khan BM, Jamil B. Causes and pattern of partial edentulism/exodontia and its association with age and gender: semi rural population, Baqai Dental college, Karachi, Pakistan. Int Dent J Stud Res. 2013 Oct;1:13-8.

[39]. Song JH, Joo SJ, Lee HS, Kang DW, Lee GJ. An occlusal contact analysis of lateral mandibular movement using T-Scan system. The J Korean Acad Prosthodont. 2015 Apr 1;53(2):128-37.

[40]. Shah SN, Khan S, Murtaza S, Ahmad A. Study of tooth wear in canine guidance versus group function occlusion. Cell. 2014;333:5079912.

[41]. Hugoson A, Bergendal T, Ekfeldt A, Helkimo M. Prevalence and severity of incisal and occlusal tooth wear in an adult Swedish population. Acta Odontol Scand. 1988 Oct;46(5):255-65.Pubmed PMID: 3264985. 